\title{
Myometrium and Sigmoid Colon Metastatic Melanoma Simulating a Ewing Tumor: A Case Report
}

\section{Adjoby Cassou Roland"1, Kouame Arthur Didier ${ }^{1 *}$, Alla Christian'1, Effoh N'Drin Denis ${ }^{1}$, Konan Joachim ${ }^{1}$, Aloui Adil ${ }^{2}$, Andriamindimbison N. Zoly ${ }^{3}$, Ahounkeng Patrick ${ }^{3}$, Birembaut Philippe ${ }^{4}$, Abboud Pascal ${ }^{3}$}

\author{
${ }^{1}$ Department of Obstetrics and Gynecology, University Hospital of Cocody, Abidjan, Côte d'Ivoire \\ ${ }^{2}$ Department of Oncology, Hospital Center of Soissons, Soissons, France \\ ${ }^{3}$ Department of Gynecology, Hospital Center of Soissons, Soissons, France \\ ${ }^{4}$ Department of Pathology, Hospital Center of Soissons, Soissons, France \\ Email: *arthur.kouame@mail.huji.ac.il
}

How to cite this paper: Roland, A.C., Didier, K.A., Christian, A., Denis, E.N., Joachim, K., Adil, A., Zoly, A.N., Patrick, A., Philippe, B. and Pascal, A. (2017) Paper Title. Open Journal of Obstetrics and $G y$ necology, 7, 897-906.

https://doi.org/10.4236/ojog.2017.78090

Received: July 1, 2017

Accepted: August 12, 2017

Published: August 15, 2017

Copyright $\odot 2017$ by authors and Scientific Research Publishing Inc. This work is licensed under the Creative Commons Attribution International License (CC BY 4.0). http://creativecommons.org/licenses/by/4.0/

\begin{abstract}
Malignant melanomas or lymphoma of the skin are malignant tumors of the skin and/or the mucous membranes whose uterine metastases are rare. The secondary uterine localizations, although rare, must be evoked in front of a pelvic tumoral syndrome, or diffuse metastases and a personal past history of melanoma, even after a long time of remission. In our observation, the evolution of the tumor in the pelvis extended to the muscular structures of the uterus and the sigmoid colon of a 72 year old patient, what made it an exceptional case. The diagnosis of these secondary localizations is a diagnosis of elimination, almost always post-operative, made on the histopathological and immunocytochemical study of the surgical specimen, supported by cytogenetics, even molecular biology. The treatment is based on chemotherapy.
\end{abstract}

\section{Keywords}

Melanoma, Uterine Metastases, Myometrium, Ewing Tumor, PNET

\section{Introduction}

Malignant melanoma or cutaneous lymphoma or lymphoma of the skin accounts for $1 \%$ of all cancers and has an incidence of 3\% - 7\% in the female genital tract, most of the cases being described in the vulva and the vagina. It is a malignant tumor of the skin or the mucous membranes, developed from melanocytes, although some cases of primitive localizations were described in pelvic 
area, in particular on the cervix [1] [2]. It is a cancer with a high metastatic potential and metastases can theoretically reach all the organs. Indeed, $20 \%$ to $30 \%$ of the patients present metastases in spite of a broad excision of the primitive tumor. Rare cases of genital metastases were described in the literature [3] [4] [5]. Their retro-uterine localization with extension to myometrium and sigmoid is exceptional, arousing the interest of such an observation. This localization poses a diagnosis problem at the clinical, radiological and pathological level because of its rarity. The diagnosis is based on a standard histological examination supplemented by immunohistochemical studies, cytogenetics and sometimes analysis in molecular biology, starting from a representative sample of the tumor.

\section{Case Report}

In the department of Gynecology in SOISSONS Hospital Center (France), we received a 72 year old patient for abdominal pain, recurrent cystitis and intestinal transit disorder, the whole evolving for six months. In her past history, she had been pregnant twice with two vaginal deliveries. She underwent 3 year ago a surgical treatment for left temporal lymphoma (cerebral lymphoma). The patient had no record of alcohol or tobacco abuse.

The clinical examination found a large abdomino-pelvic mass, hard to move with palpation. The uterine cervix was normal. However, the anterior and lateral fornix was filled by the mass at the vaginal touch. In addition, inguinal ganglionic areas were free at the palpation. A first ultrasound examination showed a poly-lobed intestinal mass of $50 \mathrm{~mm}$ of diameter located at $30 \mathrm{~mm}$ next to the top of the uterine dome. The abdomino-pelvic CT scan carried out thereafter (see Figure 1 and Figure 2) confirmed the presence of a bulky abdomino-pelvic tumor formation measuring $180 \mathrm{~mm} \times 100 \mathrm{~mm} \times 150 \mathrm{~mm}$, of probable uterine origin with a right ureter hydronephrosis. And several external iliac nodes less than $1 \mathrm{~cm}$ and an image of sigmoid diverticulosis without sign of complication were observed.

Endometrial biopsy could not be realized because of the compressive character of the mass. A second ultrasound examination 6 months later the first pointed out an abdomino-pelvic mass of $164 \mathrm{~mm} \times 105 \mathrm{~mm}$ with a repercussion on the right urinary tract and a heterogeneous uterine cavity. Ovaries were not visualized (Figure 3).

Further complementary examinations were performed such as PET-SACN and MRI before carrying out any therapeutic. The PET-SCAN was in favor of a bulky uterine tumor mass which was hyper metabolic (SUV max 27.9) at its periphery, with central necrosis which was in favor of an aggressive malignant primitive uterine tumor because of the intensity of the hypermetabolism (Figure 4 and Figure 5). The pelvic MRI confirmed a heterogeneous $200 \times 165 \times 110$ $\mathrm{mm}$ pelvic mass related to a uterine origin which posterior wall was link to the last sigmoid loop. There was no ascites. The cervix seemed normal. Considering these results, it was not possible to draw a final diagnosis with certainty. Was it a 


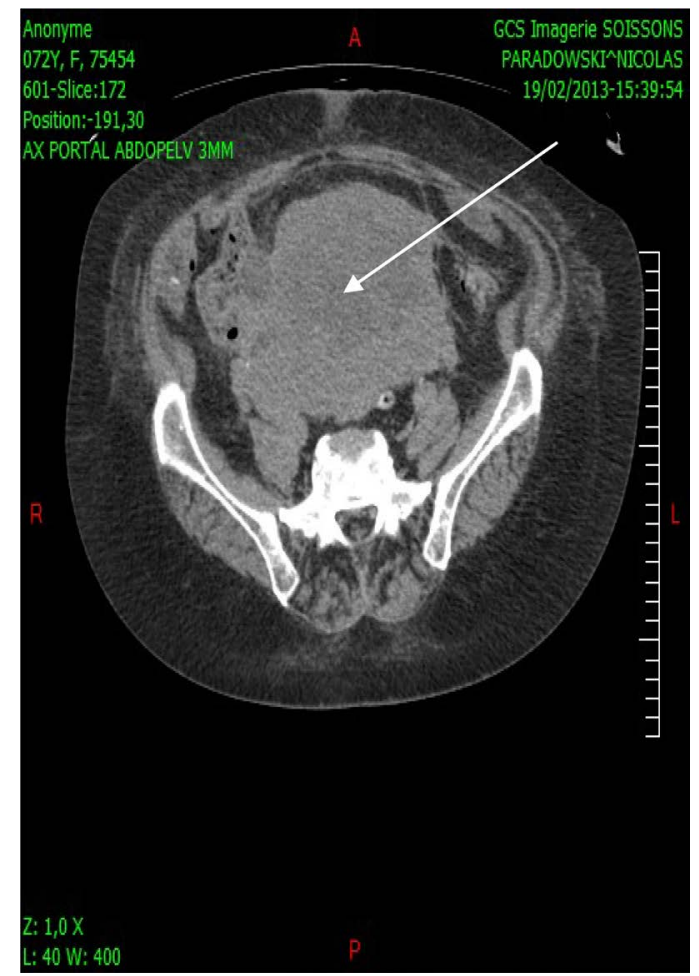

Figure 1. Showing a bulky pelvic tumor with abdominal prolongation on transverse and coronal sections (CT scan).

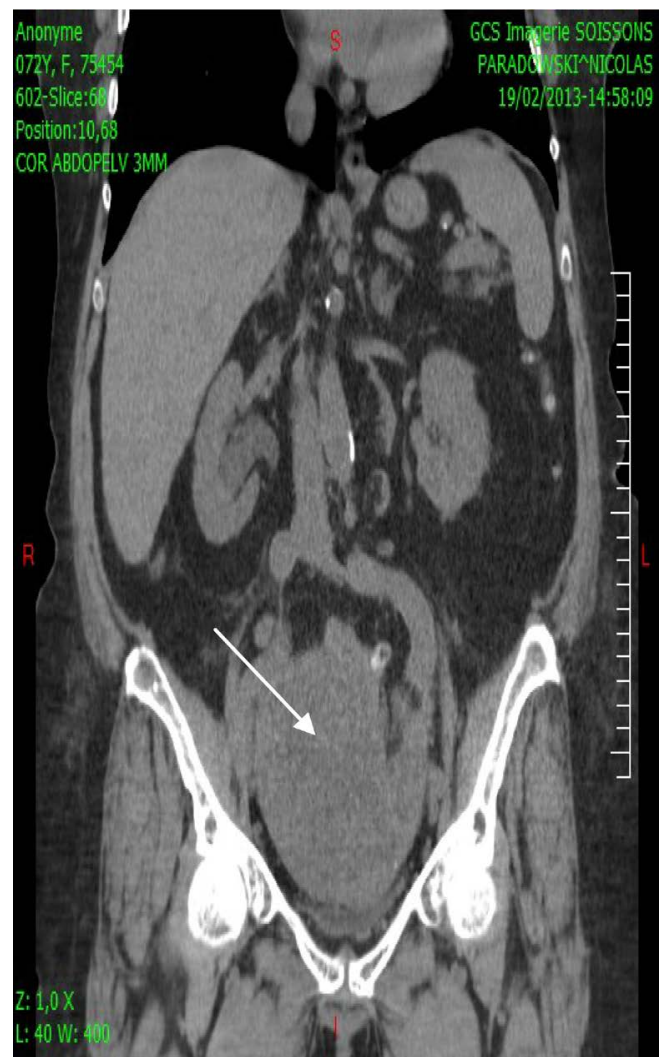

Figure 2. Showing a bulky pelvic tumor with abdominal prolongation on transverse and coronal sections (CT scan). 


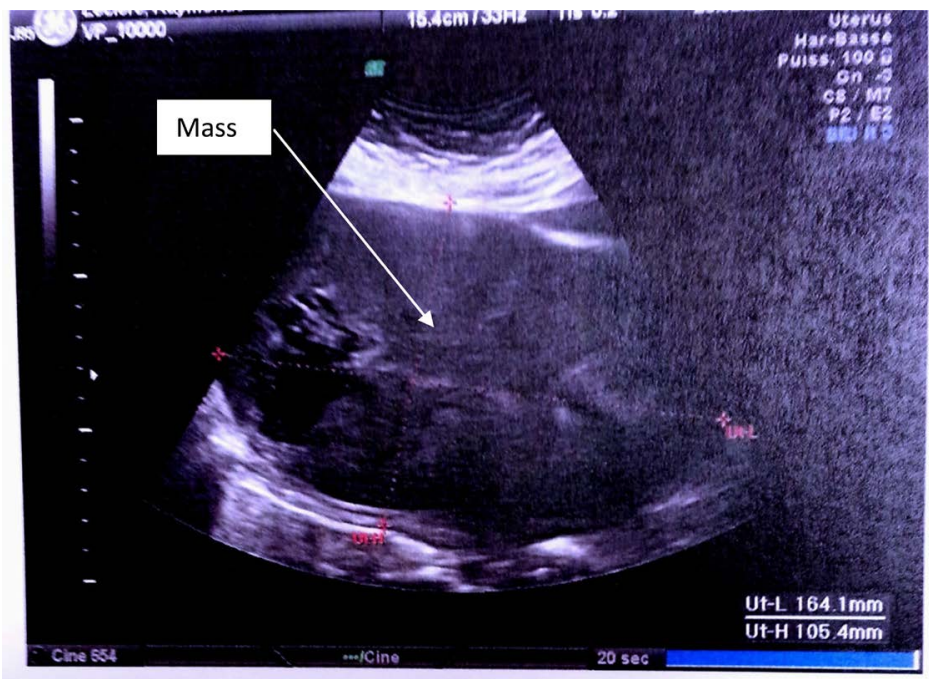

Figure 3. Ultrasound image highlighting a wide pelvic mass closely in contact with the uterus.

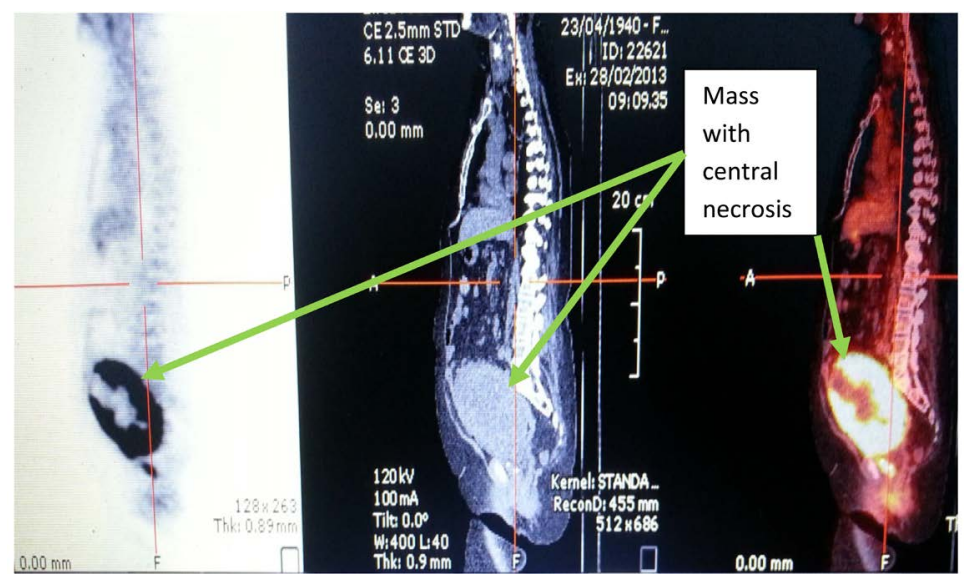

Figure 4. Image of pelvic mass with hypermetabolism after injection of 18FDG (PETSCAN)

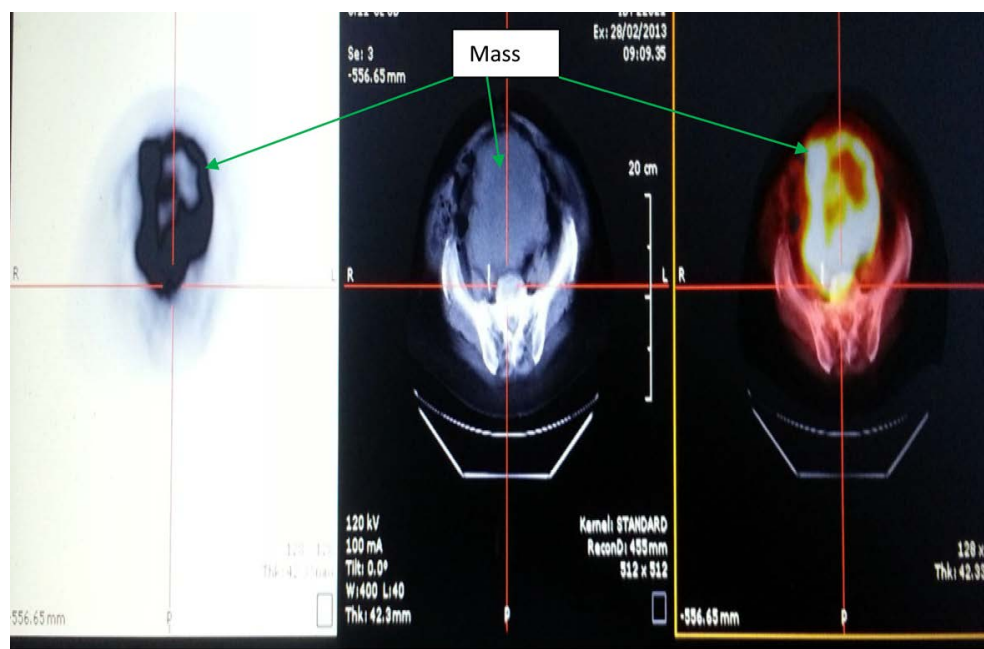

Figure 5. Image of pelvic mass with hypermetabolism after injection of 18FDG (PETSCAN). 
sarcomatous primitive uterine tumor or an evolution of the lymphoma or an association of both pathologies?

Regarding the compressive and aggressive character of the mass, it is decided to set up a double-J ureteric stent on the right before the surgical operation. A median laparotomy highlighted a pelvic mass of approximately $20 \mathrm{~cm}$ with multiple parietal adhesions. The mass adhered firmly to the sigmoid behind, the bladder ahead, and the greater omentum. There were several suspicious-looking lymph nodes on the small bowel and the mesentery. The left adnexa was not visualized and seemed to have been invaded by the tumor. The attempt to remove the tumor made necrotic tissue rose up, which had been sampled for frozen histological examination. That histopathological examination evoked a malignant tumor not well differentiated made of a proliferation of round cells particularly rich in cytonuclear atypia with a very high mitotic index (the proliferation index by Ki67 was estimated at 60\%). The cells were marked with antibodies against Vimentin, anti-CD99 antibodies and positivity with Anti-CD56 (NCAM), Anti AE1-AE3 and anti-HMB 45 (human melanoma black-45) antibodies. CD45 and Anti-protein S100 antibodies were negative. These biomarkers allowed us to eliminate a lymphoma without being able to eliminate neither a sarcoma nor a melanoma before the result of a final histological examination of the whole surgical specimen. A monobloc exeresis of the mass was performed with total hysterectomy, bilateral adnexectomy and sigmoidectomy followed by a latero-lateral colocolic anastomosis. This surgical resection allowed extracting a necrosis tumor (Figure 6).

Samples of mesenteric lymph nodes were done for a pathological examination. A per-operative blood transfusion was performed, and the Foley catheter was maintained for 10 days because of accidental urinary bladder tear that occurred during the surgical exeresis. The post-operative period was uneventful a part from a moderate anemia (hemoglobin level of $10.2 \mathrm{~g} / \mathrm{dl}$ ).

The histopathological final analysis of the surgical specimen revealed a tumor proliferation made of monomorphic cellular elements of medium size, showing very important cytonuclear atypia with many mitoses, beaches of necrosis more or less hemorrhagic, tablecloths of cells often not well differentiated. This tumor

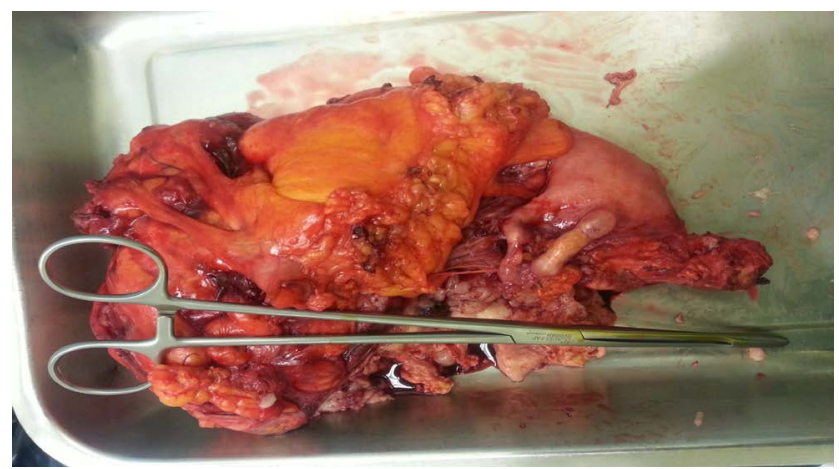

Figure 6. Surgical specimen presenting a tumor of big size forming a compact block with epiploon, sigmoid and uterus. 
infiltrated the myometrium and the muscular part of the sigmoid without real sigmoid tumor. Lymph nodes samples were not invaded and the appendix was normal. The histopathological diagnosis was in favor of a round cells very little differentiated tumor formation of pelvic localization encompassing the uterus and the sigmoid which might be a Primitive Neuro-Ectodermic Tumor (PNET) or melanoma. An expert testimony was required for a histopathology second reading and the search for a possible translocation. Therefore, the search for translocation and mutations of the site of exon 15 of BRAF gene was negative. Finally, the diagnosis of metastatic melanoma was retained in front of a disseminated tumor without a clear starting point. The patient was put under Dacarbazine protocol. The exit of the patient was decided at the $15^{\text {th }}$ day of hospitalization.

\section{Discussion}

The incidence of melanoma doubles approximately every ten years in caucasian countries. In France, cutaneous melanoma represents in 2011 the $6^{\text {th }}$ cause of woman cancer with 5100 estimated new cases. It occurs in $75 \%$ of cases after 49 years. Cutaneous melanomas represent the $14^{\text {th }}$ cause of woman death with estimated 720 deaths for year 2011 [6]. The exceptional metastatic potential of the melanoma is due to the reactivation of a gene named slug during the cancerization. That gene allows the migration in the embryo of cells coming from neural crest, whose melanocytes are part of [7]. The most common localizations of metastatic lesions are by decreasing order: the lung (42\%), the skin and node areas (18\%), the brain (14\%), the liver (7\%) and other rarer sites such as bones, spleen, breast, ovaries, corpus uteri [3]. Uterine metastasis of the melanoma is exceptional and most often come from a primitive cancer of breast, digestive tube, lung, pancreas, kidney or skin [5]. These metastases generally concern the myometrium as it is the case in our observation [3] [5] [8]. Time period between primitive cancer and the metastasis is often long of several years and metrorrhagias represent the main symptoms of the disease [3]. In our case, the patient had a history of cerebral lymphoma. She did not suffer from post-menopausal metrorrhagias that could direct towards an endometrial cancer. She had a predominance of loco-regional symptoms showing of a fast growth of the tumor, affecting probably the myometrium. This situation is the privilege of PNET (Primitive neuro-ectodermic tumors). Indeed, the period (between the beginning of the primary symptoms and the histopathological diagnosis of certainty) is theoritically less than one year because of the generally the aggressive character of the PNET [9]. Also, the diagnosis of metastases of soft parts cannot be a clinical diagnosis because of the diversity of the symptoms [10]. Thus, according to most authors, the diagnosis can be made generally a posteriori, on the surgical specimen after several readings supported by immunohistochemistry and experienced pathologists. Nevertheless, there exists a genetic predisposition. Melanoma patients ( $5 \%$ to $10 \%$ ) have a family history of this disease. A mutation on CDKN2A 
gene located on chromosome 9 and on CDK4 gene located on chromosome 12 leads to the appearance of the melanoma [11]. A mutation on BRAF gene coding for a kinase is present in more than one case on two (50\% to 60\%) of metastatic melanomas [12] [13]. No radio-anatomic correlation is published at this day, because of the scarcity of secondary localizations of the melanomas. The main role of the imagery is to search a primitive tumor and to determine the local and remote extension, in order to consider the surgical exeresis. Today there is positron emission tomography (PET-SCAN) which differs considerably from the means of conventional imagery. That is about a metabolic method aiming at analyzing the functional activity of tissues and not its morphological anomalies. In our observation, imagery did not reveal a primitive tumor, but directed toward the aggressive character of the tumor. The PET-SCAN could be integrated in the cancer staging of patients with a high metastatic risk [14]. Ultimately, the histopathologic study associated with the immunohistochemistry is a fundamental stage of the diagnosis [2] [3] [5] [8] [9]. It is subjected to difficulties related to the rarity of these metastatic forms. Our patient underwent a total abdominal hysterectomy associated with a bilateral adnexectomy in order to fulfill the surgical technique for cancer requirement. This surgery allowed the diagnosis and started the treatment. Nevertheless, in case of doubt about the margins of resection as it was the case, adjuvant chemotherapy in specialized center is required. The macroscopic examination of the surgical specimen showed a tumor of soft consistency, necrosis aspect, frequently met in PNET [15]. On the histological level, it was about proliferations of small basophilic round cells with a neuro-ectodermal phenotype. The immunohistochemistry once carried out, will contribute to the differential diagnosis of small round cells malignant tumors (PNET, lymphomas, neuroblastoma, nephroblastoma, rhabdoid tumor, rhabdomyosarcoma and neuroendocrine carcinoma...) [9] [16]. Indeed, melanomas present a cellular positivity with S-100 protein, melana and HMB-45 as it was the case for our patient. Considering the positivity of the CD99 immunophenotype found in more than $90 \%$ of PNET, the cytogenetic study and molecular biology were required to establish the diagnosis formally. The search for translocation and BRAF gene returned negative. Consequently, the existence of specific genetic markers, highlighted preferentially on fresh or frozen tissues and signing the nature of the disease, justifies the conservation of frozen tumor tissue. The uterine manifestation of a malignant melanoma being rare, is most often the result of a metastasis rather than of a primitive tumor [2]. In addition, the results of meticulous patient interview, clinical and paraclinical evaluation should be communicated to the pathologists, enabling them to retain the final diagnosis of metastatic melanoma [3] [8]. This measure would allow an optimal management in multidisciplinary meeting in order to avoid useless and mutilating procedures for patients whom prognosis is not favorable.

The first line treatment of metastatic melanomas rests on chemotherapy. The drug used is Dacarbazine for all metastases except for cerebral metastases, for 
which the Fotemustine should be sought in preference. Dacarbazine is administered in cures of 1 - 4 days every 3 - 4 weeks. In case of operable unique or multiple metastases (for example in only one organ), surgery can be considered as first line treatment regarding clinical and radiological examinations. Radiotherapy is an alternative treatment in particular case of cerebral or bone metastases, but not generally used. Two new treatments have just obtained the marketing authorization as well as refunding. The unaffordable prices $(€ 60,000)$ of these drugs which can be an obstacle in case of none refunding in some countries. These are Ipilimumab and Vemurafenib. Ipilimumab is an immunotherapy aiming at stimulating the immune system by inhibiting the CTLA4. Ipilimumab works for $20 \%$ of patients but with survival medians of 24 months. Vemurafenib, a targeted therapy specifically is directed against the BRAF gene, prescribed in first line if the BRAF gene is muted [17] [18] [19]. It works for $60 \%$ of the patients but with survival medians not exceeding 7.2 months.

The prognosis of uterine metastases of the melanomas could have a great improvement in the coming years. However, at present time the survival median at the metastatic stage is of $10-20$ months with a 5-year survival rate of approximately 5\% [20] [21]. The late recurrences after 10 years are possible and often hard to diagnose [3].

\section{Conclusion}

Uterine metastasis of the melanomas is rare and of bad prognosis. The contribution of clinical examination and imagery in the diagnosis is weak. The diagnosis has to be done early because survival of the patients depends on it. Pathologists struggle to make a clear diagnosis. Immunohistochemistry and cytogenetics are helpful tools. The increasing incidence of the melanomas could lead to more cases in the future. Gynecologists should be prepared to face such situations. Ultimately, the complexity of managing metastatic melanoma cases teaches us to have multidisciplinary meeting discussions in specialized center, if we expect to increase survival of patient in the future.

\section{Acknowledgments}

We wish to acknowledge Dr Joanna Stephens and the clinical staff as well as the pathology laboratory staff for their support in the preparation of this manuscript.

\section{References}

[1] Simões, M., Cunha, V., Nabais, H., Riscado, I. and Jorge, A.F. (2011) Primary Malignant Melanoma of the Uterine Cervix a Case Report and Review. European Journal of Gynaecological Oncology, 32, 448-451.

[2] Boldt, C., Lehmann, R., Osmers, R. and Bürrig, K.F. (2003) Mélanome malin primitif du col utérin. Rapport de deux cas et revue de la littérature. Pathologie, 24, 226-235

[3] Sans-Michel, A.C., Trastour, C., Piche, M., Delotte, J., Cohen-Scali, P., Azuar, P. 
and Bongain, A. (2011) Le gynécologue face au mélanome: Métastases utérines et mammaires à propos de 3 cas. Journal de Gynécologie Obstétrique et Biologie de la Reproduction, 40, 359-362. https://doi.org/10.1016/j.jgyn.2010.09.006

[4] Nagy, P., Csaba, I. and Kadas, I. (1990) Malignant Melanoma Metastatic to the Endometrium. Cytologic Findings in a Direct Endometrial Sample. Acta Cytologica, 34, 382-384.

[5] Di Tommaso, L., Rahal, D., Bresciani, G. and Roncalli, M. (2005) Cutaneous Melanoma Metastatic to Uterine Adenomyoma: Report of a Case. International Journal of Surgical Pathology, 13, 223-225. https://doi.org/10.1177/106689690501300217

[6] Thuret, A. (2012) L'épidémiologie du mélanome cutané en France et en Europe. Bulletin épidémiologique hebdomadaire, Institut de veille sanitaire, Saint-Maurice, 213-214.

[7] Fenouille, N., Tichet, M., Dufies, M., Pottier, A., Mogha, A., Soo, J.K., Rocchi, S., Mallavialle, A., Galibert, M.D., Khammari, A., Lacour, J.P., Ballotti, R., Deckert, M. and Tartare-Deckert, S. (2012) The Epithelial-Mesenchymal Transition (EMT) Regulatory Factor SLUG (SNAI2) Is a Downstream Target of SPARC and AKT in Promoting Melanoma Cell Invasion. PloS One, 7, 40378. https://doi.org/10.1371/journal.pone.0040378

[8] Berker, B., Sertcelik, A., Kaygusuz, G., Unlu, C. and Ortac, F. (2004) Abnormal Uterine Bleeding as a Presenting Sign of Metastasis to the Endometrium in a Patient with a History of Cutaneous Malignant Melanoma. Gynecologic Oncology, 93, 252256. https://doi.org/10.1016/j.ygyno.2004.01.012

[9] Fekak, H., Rabii, R., Moufid, K., Mezzour, H., Joual, A., Badre, L., El Attar, Iraqui, A., Bennani, S. and El Mrini, M. (2002) Les tumeurs neuro ectodermiques périphériques primitives des parties molles à propos d'un cas. African Journal of Urology, 8, 143-148.

[10] Plaza, J.A., Perez-Montiel, D., Mayerson, J., Morrison, C. and Suster, S. (2008) Les métastases des tissus mous: Un examen des 118 cas sur une période de 30 ans. Cancer, 112, 193-203. https://doi.org/10.1002/cncr.23151

[11] Bataille, V. and de Vries, E. (2008) Melanoma Part 1: Epidemiology, Risk Factors, and Prevention. BMJ, 337, a2249. https://doi.org/10.1136/bmj.a2249

[12] Davies, H., Bignell, G.R., Cox, C., et al. (2002) Mutations of the BRAF Gene in Human Cancer. Nature, 417, 949-954. https://doi.org/10.1038/nature00766

[13] Curtin, J.A., Fridlyand, J., Kageshita, T., et al. (2005) Distinct Sets of Genetic Alterations in Melanoma. The New England Journal of Medicine, 353, 2135-2147. https://doi.org/10.1056/NEJMoa050092

[14] Wagner, J.D., Schauwecker, D., Davidson, D., Logan, T., Coleman 3rd, J.J., Hutchins, G., et al. (2005) Inefficacy Scans for Initial of F-18 Fluoro Desoxy- D-Glucose Positron Tomography Scans for Initial Evaluation in Early-Stage Cutaneous Melanoma. Cancer, 104, 570-579. https://doi.org/10.1002/cncr.21189

[15] Ayadi, L., Châari, C., Kallel, R., Ayadi, K., Khabir, A., Jlidi, R., Daoud, J., Frikha, M., Makni, S., Sellami-Boudawara, T., d'Ewing Osseux, S., et al. (2010) Extra Osseux: Etude Anatomo-Clinique de 29 cas. La Tunisie Médicale, 88, 301-305.

[16] Tsai, H.J., Su, C.-F., Kok, V.C. and Li, M.C. (2012) Uterine Tumor with Neuroectodermal Differenciation of Advanced Stage Managed Successfully with Multimodal Strategy. European Journal of Obstetrics, Gynecology, and Reproductive Biology, 162, 235 236. https://doi.org/10.1016/j.ejogrb.2012.02.011

[17] Robert, C., Thomas, L., Bondarenko, I., O'Day, S., MD, J.W., Garbe, C., Lebbe, C., 
Baurain, J.F., Testori, A., Grob, J.J., Davidson, N., Richards, J., Maio, M., Hauschild A., Miller Jr., W.H., Gascon, P., Lotem, M., Harmankaya, K., Ibrahim, R., Francis, S., Chen, T.T., Humphrey, R., Hoos, A. and Wolchok, J.D. (2011) L'ipilimumab, plus la Dacarbazine Pour les Mélanomes Métastatiques non Préalablement Traités. The New England Journal of Medicine, 364, 2517-2526. https://doi.org/10.1056/NEJMoa1104621

[18] Flaherty, K.T., Puzanov, I., Kim, K.B., et al. (2010) Inhibition of Mutated, Activated BRAF in Metastatic Melanoma. The New England Journal of Medicine, 363, 809819. https://doi.org/10.1056/NEJMoa1002011

[19] Hodi, F.S., O'Day, S.J., McDermott, D.F., et al. (2010) Improved Survival with Ipilimumab in Patients with Metastatic Melanoma. The New England Journal of Medicine, 363, 711-723. https://doi.org/10.1056/NEJMoa1003466

[20] Vaughan, A., Dietz, J.R., Moley, J.F., Debenedetti, M.K., Aft, R.L., Gillanders, W.E., et al. (2007) Metastatic Disease to the Breast: the Washington University Experience. World Journal of Surgical Oncology, 5, 74.

https://doi.org/10.1186/1477-7819-5-74

[21] Gupta, D., Deavers, M.T., Silva, E.G. and Malpica, A. (2004) Malignant Melanoma Involving the Ovary: a Clinicopathologic and Immunohistochemical Study of 23 Cases. The American Journal of Surgical Pathology, 28, 771-780. https://doi.org/10.1097/01.pas.0000126786.69232.55

Submit or recommend next manuscript to SCIRP and we will provide best service for you:

Accepting pre-submission inquiries through Email, Facebook, LinkedIn, Twitter, etc. A wide selection of journals (inclusive of 9 subjects, more than 200 journals) Providing 24-hour high-quality service User-friendly online submission system Fair and swift peer-review system Efficient typesetting and proofreading procedure Display of the result of downloads and visits, as well as the number of cited articles Maximum dissemination of your research work

Submit your manuscript at: http://papersubmission.scirp.org/ Or contact ojog@scirp.org 